\title{
Operando XAS Study of the Surface Oxidation State on a Monolayer IrOx on RuOx and Ru Oxide Based Nanoparticles for Oxygen Evolution in Acidic Media
}

Pedersen, Anders Filsøe; Escribano, Maria Escudero; Sebok, Bela; Bodin, Anders; Paoli, Elisa Antares; Frydendal, Rasmus; Friebel, Daniel; Stephens, Ifan; Rossmeisl, Jan; Chorkendorff, Ib Total number of authors: 11

Published in: Journal of Physical Chemistry Part B: Condensed Matter, Materials, Surfaces, Interfaces \& Biophysical

Link to article, DOI:

10.1021/acs.jpcb.7b06982

Publication date:

2018

Document Version

Peer reviewed version

Link back to DTU Orbit

Citation (APA):

Pedersen, A. F., Escribano, M. E., Sebok, B., Bodin, A., Paoli, E. A., Frydendal, R., Friebel, D., Stephens, I., Rossmeisl, J., Chorkendorff, I., \& Nilsson, A. (2018). Operando XAS Study of the Surface Oxidation State on a Monolayer IrO on RuO and Ru Oxide Based Nanoparticles for Oxygen Evolution in Acidic Media. Journal of Physical Chentistry Part ${ }^{x}$ : Condensed Matter, Materials, Surfaces, Interfaces \& Biophysical, 122(2), 878-887. https://doi.org/10.1021/acs.jpcb.7b06982

\section{General rights}

Copyright and moral rights for the publications made accessible in the public portal are retained by the authors and/or other copyright owners and it is a condition of accessing publications that users recognise and abide by the legal requirements associated with these rights.

- Users may download and print one copy of any publication from the public portal for the purpose of private study or research.

- You may not further distribute the material or use it for any profit-making activity or commercial gain

- You may freely distribute the URL identifying the publication in the public portal 
Operando XAS Study of the Surface Oxidation State on a Monolayer IrO $\mathrm{x}_{\mathrm{x}}$ on $\mathrm{RuO}_{\mathrm{x}}$ and $\mathrm{Ru}$ Oxide Based Nanoparticles for Oxygen Evolution in Acidic Media Anders F. Pedersen ${ }^{\mathrm{a}}$, Maria Escudero-Escribano ${ }^{\mathrm{a}, \mathrm{b}, \mathrm{c}}$, Bela Sebok ${ }^{\mathrm{a}}$, Anders Bodin ${ }^{\mathrm{a}}$, Elisa Paolia, Rasmus Frydendal ${ }^{\mathrm{a}}$, Daniel Friebel ${ }^{\mathrm{c}}$, Ifan E. L. Stephens ${ }^{\mathrm{a}, \mathrm{d}}$, Jan Rossmeis| ${ }^{\mathrm{b}}$, Ib Chorkendorffa, Anders Nilsson ${ }^{\mathrm{e}}$. ${ }^{a}$ Department of Physics, Technical University of Denmark, 2800 Kongens Lyngby, Denmark.

${ }^{\mathrm{b} D e p a r t m e n t}$ of Chemistry, University of Copenhagen, 2100 København, Denmark.

'SUNCAT Center for Interface Science and Catalysis, Department of Chemical Engineering, Stanford University, CA 94305, United States.

dDepartment of Materials, Imperial College, Exhibition Road, London SW7 2AZ, United Kingdom eFysikum, Stockholm University, 10691 Stockholm, Sweden.

*Corresponding author, email: andersn@fysik.su.se 


\section{Abstract}

Herein we present surface sensitive operando XAS L-edge measurements on $I \mathrm{rO}_{\mathrm{x}} / \mathrm{RuO}_{2}$ thin films as well as mass-selected $\mathrm{RuO}_{\mathrm{x}}$ and Ru nanoparticles. We observed shifts of the white line XAS peak towards higher energies with applied electrochemical potential. Apart from the case of the metallic Ru nanoparticles, the observed potential dependencies were purely core-level shifts caused by a change in oxidation, which indicates no structural changes. These findings can be explained by different binding energies of oxygenated species on the surface of $\mathrm{IrO}_{\mathrm{x}}$ and $\mathrm{RuO}_{\mathrm{x}}$. Simulated XAS spectra show that the average Ir oxidation state change is strongly affected by the coverage of atomic $O$. The observed shifts in oxidation state suggests that the surface has a high coverage of $\mathrm{O}$ at potentials just below the potential where oxygen evolution is exergonic in free energy. This observation is consistent with the notion that the metal-oxygen bond is stronger than ideal. 


\section{Introduction}

Our current dependence on fossil fuels is being challenged, and many countries are switching to an increasing amount of renewable energy generation due to a combination of economic and political incentives ${ }^{1}$. However, most of the new energy sources are producing electricity intermittently, such as wind turbines and solar panels. Today the intermittent power supply is offset by existing fossil fuel power plants, but as the wind- and solar-power fractions increase further this is no longer viable, and new approaches to storing the produced electrical energy are needed. One possibility of storing the energy is in the form of chemical bonds, in which energy conversion devices convert excess electricity into easily storable chemicals, and convert them back to electricity on demand ${ }^{2}$.

For such energy storage technologies to be viable, it is necessary to develop efficient devices that convert electric energy into chemical bonds. This can be in principle obtained in electrochemical cells, but for most relevant electrochemical reactions we do not have catalysts that are efficient enough to avoid large energy-losses. One particularly important chemical reaction is the oxygen evolution reaction (OER: $2 \mathrm{H}_{2} \mathrm{O} \rightarrow 4 \mathrm{H}^{+}+4 e^{-}+\mathrm{O}_{2}$ ), which is one of the half-cell reactions in water splitting. Most synthetic fuels require hydrogen: for instance, dihydrogen is obtained from the hydrogen evolution reaction (HER: $\left.2 \mathrm{H}^{+}+2 e^{-} \rightarrow \mathrm{H}_{2}\right)^{3}$, whereas $\mathrm{CO}_{2}$ can be reduced to hydrocarbons (e.g. $\left.\mathrm{CO}_{2}+8 \mathrm{H}^{+}+8 e^{-} \rightarrow \mathrm{CH}_{4}+2 \mathrm{H}_{2} \mathrm{O}\right)^{4}$. However, in both these cases the source of hydrogen is water splitting, and so the OER must be an integral part of the device. Proton exchange membrane (PEM) ${ }^{5}$ electrolyzers, which use acidic electrolyte, have several benefits over traditional alkaline electrolyzers, such as higher current densities and better safety ${ }^{6,7}$. 
It is a challenge to find materials that are both active for OER and stable in acidic conditions at the highly oxidative potentials required for water splitting. Most catalysts today are based on the precious metals Ir and $\mathrm{Ru}^{8-14}$. In terms of scaling up energy conversion on a global scale this presents a significant problem, as these metals are extremely scarce ${ }^{15}$. $\mathrm{RuO}_{\mathrm{x}}$ and $\mathrm{IrO}_{\mathrm{x}}$ have shown promising activity for the $\mathrm{OER}^{10,12,16-24}$, albeit most forms of $\mathrm{RuO}_{\mathrm{x}}$ present poor stability ${ }^{11,22,25}$. The sample preparation conditions have a great impact on the activity and stability of $\mathrm{RuO}_{\mathrm{x}}$ based OER catalysts ${ }^{26}$, so even the performance of a single material $\left(\mathrm{RuO}_{x}\right)$ can vary greatly ${ }^{25,27,28}$.

Rossmeisl, Nørskov and coworkers developed a theoretical model to elucidate trends in oxygen evolution activity, using a density functional theory (DFT) based model. ${ }^{29-31}$ They proposed the following mechanism, based on four coupled electron-proton transfers:

$$
\begin{aligned}
& *+\mathrm{H}_{2} \mathrm{O} \rightarrow * \mathrm{OH}+\mathrm{e}^{-}+\mathrm{H}^{+} \\
& * \mathrm{OH} \rightarrow * \mathrm{O}+\mathrm{e}^{-}+\mathrm{H}^{+} \\
& * \mathrm{O}+\mathrm{H}_{2} \mathrm{O} \rightarrow * \mathrm{OOH}+\mathrm{e}^{-}+\mathrm{H}^{+} \\
& * \mathrm{OOH} \rightarrow *+\mathrm{O}_{2}+\mathrm{e}^{-}+\mathrm{H}^{+}
\end{aligned}
$$

where ${ }^{*}$ represents an active catalytic site. Using the free energies of each step calculated in ${ }^{30}$, a free energy diagram can be constructed for the entire reaction on $\mathrm{RuO}_{2}(110)$ surface at different potentials, as seen in Figure 1. 


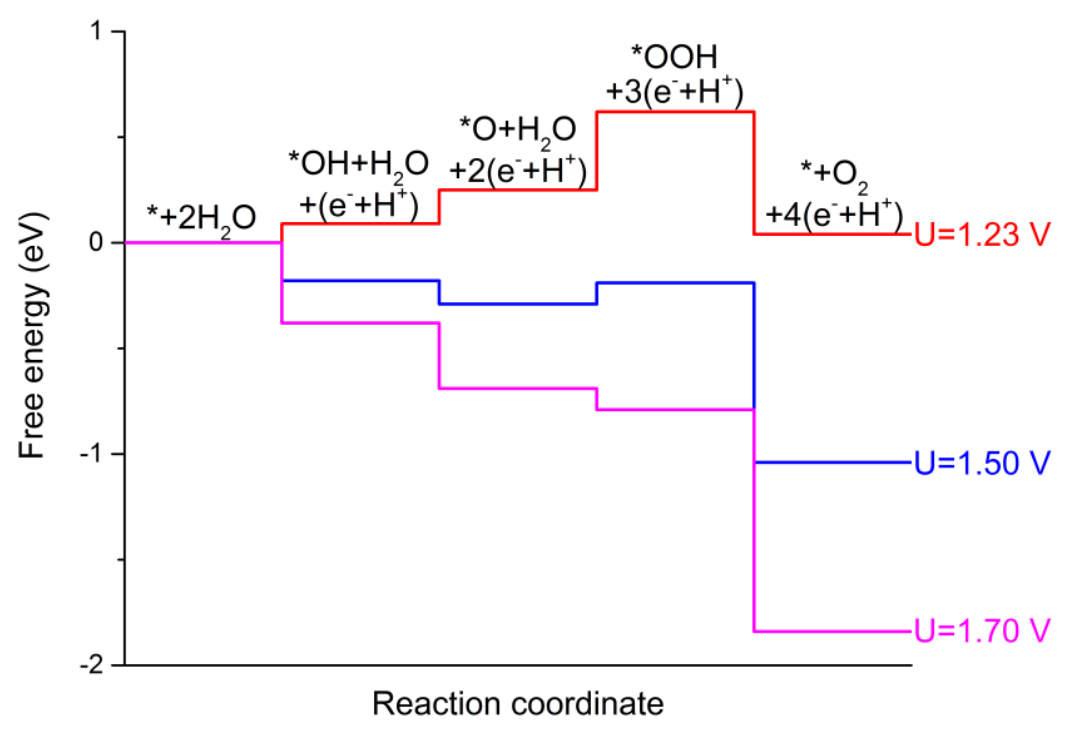

Figure 1. A free energy diagram of the OER mechanism described in the text on a $\mathrm{RuO}_{2}(110)$ surface, based on free energy DFT calculations in reference ${ }^{30}$. For these calculations, the thermodynamic OER onset is at $1.60 \mathrm{~V}$, the point at which all steps become downhill in energy. The free energy diagram has been calculated at the equilibrium potential $1.23 \mathrm{~V}$, just below the OER onset at $1.50 \mathrm{~V}$, and just above the OER onset at $1.70 \mathrm{~V}$. All potentials are given vs. the reversible hydrogen electrode (RHE).

The ideal catalyst would have a completely flat free energy profile at the equilibrium potential, $1.23 \mathrm{~V}$. However, it turns out that there is a constant energy difference between the binding energies of the two intermediates, ${ }^{*} \mathrm{OH}$ and ${ }^{*} \mathrm{OOH}$. This means that even on the best catalyst, there is significant corrugation at the equilibrium potential; overcoming this corrugation requires an overpotential equal in magnitude to the most uphill step. On the most optimal catalyst (as opposed to the aforementioned ideal catalyst), the free energy change between $\mathrm{O} *$ formation and $\mathrm{OOH}^{*}$ formation 
would be equal. On a surface which binds $* \mathrm{O}$ too weakly, relative to $* \mathrm{OH}$, the overpotential will be due to $* \mathrm{O}$ formation. Conversely, a surface which binds * O too strongly, relative to * $\mathrm{OH}$ (and by extension $\left.{ }^{*} \mathrm{OOH}\right)$, the overpotential will be due to the ${ }^{*} \mathrm{OOH}$ formation. According to Figure 1 , the latter is the case for $\mathrm{RuO}_{2}(110)$, where ${ }^{*} \mathrm{OOH}$ formation is uphill by $0.37 \mathrm{eV}$ at $1.23 \mathrm{~V}$, while on $\mathrm{IrO}_{2}(110)$ this step is $0.65 \mathrm{eV}$ uphill ${ }^{31}$. These trends result in a Sabatier volcano relationship ${ }^{31}$.

In the current paper, our goal is to probe the proposed reaction mechanism and binding of the intermediates by performing operando x-ray measurements. L-edge spectroscopy of the metal atoms using hard X-rays is a bulk sensitive method; even though earlier studies of oxygen reduction on Pt showed that high spectral sensitivity from the interface can be obtained using monolayer catalysts ${ }^{32}$ and small nanoparticles ${ }^{33}$. Herein, we have used a similar approach to investigate the L-edge of Ir and Ru during OER by depositing monolayer amounts of $\mathrm{IrO}_{\mathrm{x}}$ on $\mathrm{RuO}_{2}$ and small nanoparticles of Ru metal and $\mathrm{RuO}_{2}$. We compared the measured Ir XAS spectra to that of simulated spectra to further connect the reaction mechanism to our measurements. For the simulations, we have chosen the four intermediates mentioned in the proposed reaction mechanism above (empty site, ${ }^{*} \mathrm{OH},{ }^{*} \mathrm{O}$, and $\left.{ }^{*} \mathrm{OOH}\right)$, as well as an *OO-based intermediate. The latter has been predicted theoretically ${ }^{34}$ and observed experimentally ${ }^{35}$.

For applications in PEM electrolyzers, nanoparticulate Ir or Ru-based catalysts are often preferred, as they provide a higher surface area per mass of catalyst used. Thus, understanding the catalytic behavior of $\mathrm{Ru}$ and $\mathrm{RuO}_{2}$ in their nanoparticulate form is critical. Therefore, we investigated massselected metallic $\mathrm{RuO}_{\mathrm{x}} / \mathrm{Ru}$ and thermally oxidized $\mathrm{RuO}_{2}$ nanoparticles produced by magnetron sputtering and gas aggregation ${ }^{36}$, which we reported previously ${ }^{10}$; this production method ensures 
good control of the size and morphology of the catalyst material. As nanoparticles have a high surface-to-bulk ratio they also present a system well suited for studying surface phenomena using Xray absorption spectroscopy (XAS). Likewise, the ultra-thin $\mathrm{IrO}_{\mathrm{x}}$ films ${ }^{37}$ gave uniquely surface sensitive XAS measurements. To properly understand the reaction mechanism, we investigated all samples under operando conditions, having conditions as close as possible to real OER conditions. Catalytic reactions typically take place at the surface; hence their elucidation requires surface sensitive probes. Moreover, as emphasized by Miquel Salmeron and co-workers, measurements under reaction conditions are essential to fully understand surface chemical reactions ${ }^{38-40}$.

Previously OER has been investigated using operando XAS and XPS on $\mathrm{IrO}_{\mathrm{x}}$ nanoparticles ${ }^{41,42}$, as well as on pure Ir or Ru films ${ }^{11}$ and mixed Ir/Ru compound thin films ${ }^{43}$. Here we show that the L-edge XAS white line, corresponding to $\mathrm{p}$ to $\mathrm{d}$ excitations of both Ir and $\mathrm{Ru}$, are sensitive to the applied potential with a shift towards higher photon energies approaching OER conditions. This is most noticeable for the sub-monolayer of $\mathrm{IrO}_{\mathrm{x}}$ that gives a maximum surface sensitivity since all Ir atoms are at the interface. The measurements presented here have a higher energy resolution than previously reported XAS spectra, as we are using the Ru L-edge (instead of the K-edge) and a special high energy resolution XAS technique on the Ir L-edge. The adsorbed $\mathrm{O}$ atoms cause a change in the oxidation state of the Ir atom, in agreement with previous operando $x$-ray photoelectron spectroscopy studies of $\mathrm{IrO}_{2}$ nanoparticles ${ }^{42}$. The results give important insights into the reaction mechanism by detecting that the adsorbed $\mathrm{O}$ atoms are the stable intermediate providing support for the proposed theoretical mechanism ${ }^{30}$. 


\section{Experimental setup}

\section{Sample preparation}

The hybrid $\mathrm{IrO}_{x} / \mathrm{RuO}_{2}$ system was tested by depositing $2 \AA$ of $\mathrm{IrO}_{\mathrm{x}}$ on top of a $40 \mathrm{~nm} \mathrm{RuO}_{2}$ thin film. Both films were deposited by magnetron sputtering of a Ru or Ir target at $30 \mathrm{~W}$ with the sample substrate being held at $300^{\circ} \mathrm{C}$. The oxide was formed during sputtering by a reactive atmosphere at 3 mTorr and a flow of $10 \mathrm{sccm} \mathrm{Ar}$ and $4 \mathrm{sccm} \mathrm{O}_{2}$. The sputter rate was monitored by a quartz crystal microbalance (QCM). Samples of $40 \mathrm{~nm} \mathrm{RuO} 2$ thin film were deposited on polycrystalline Au disks, followed by the deposition of $2 \AA$ of $\operatorname{IrO}_{x}$ (sample $2 \AA$ IrO $x / \mathrm{RuO}_{2} / \mathrm{Au}$ ). After the deposition, the substrate was held at $300^{\circ} \mathrm{C}$ for 30 minutes for annealing. Considering a conservative roughness factor of 2 for the $\mathrm{RuO}_{2}$ thin film, the $2 \AA$ film thickness of IrO $_{x}$ correspond to sub-monolayer coverage.

The mass-selected ruthenium nanoparticles were prepared under ultra-high vacuum (UHV) using a nanoparticle source equipped with a magnetron sputter gas-aggregation source coupled to a lateral time-of-flight mass filter. The production method can be described in five steps: 1) A ruthenium metal target was sputtered with $\mathrm{Ar}^{+}$-ions in a DC magnetron sputter head, 2) the sputtered metal atoms were allowed to condense into nanoparticles in a liquid $\mathrm{N}_{2}$ cooled "aggregation zone", where He gas was added to facilitate aggregation ${ }^{36}$. The total pressure in the aggregation zone was in the order of 0.4 mbar. 3) The nanoparticles exited the aggregation zone through an aperture to a differentially pumped region, thus undergoing a supersonic expansion. The nanoparticles then entered an electric lens system, where the negatively charged particles were focused into a narrow beam. 4) The particles were mass-filtered in a lateral time-of-flight mass filter with a resolution of $m / \Delta m=20^{44}$, set to select particles with a mass of $500,000 \mathrm{amu}$, corresponding to $5 \mathrm{~nm}$ in diameter assuming spherical 
shape and the bulk density of Ru. 5) The particles were deposited on the glassy carbon substrates supported by steel frames, through an aperture with a diameter of $9 \mathrm{~mm}$, yielding a total loading of about $400 \mathrm{ng}$. One set of nanoparticles were subsequently oxidized at $400{ }^{\circ} \mathrm{C}$ in a flow of pure $\mathrm{O}_{2}$ for 1 minute, while the other sample got oxidized by being exposed to air for 72 hours.

The used apparatus was a Nano-Beam 2011 nanoparticle source (Birmingham Instruments Inc.), which has a base pressure in the low $10^{-10}$ mbar range. For more information about the preparation of mass selected nanoparticles see earlier papers from our laboratory. ${ }^{26,45,46}$

The nanoparticle source is coupled to another UHV system (Scienta Omicron Multiscan Lab XP), where XPS characterization was conducted using a SPECS XR 50 X-ray gun coupled to an Omicron NanoSAM 7 channel energy analyzer. This chamber has a base pressure in the low $10^{-11} \mathrm{mbar}$ range. The coupling of the two vacuum chambers allows XPS to be carried out after deposition without exposing the nanoparticles to air.

In order to verify that the nanoparticle mass-selection had resulted in a narrow size-distribution, Ru nanoparticles were deposited on CU TEM grids with a lacey carbon support layer under the same deposition conditions as the samples. One grid was exposed to the same oxidation heat treatment as the glassy carbon windows $\left(400{ }^{\circ} \mathrm{C}\right.$ for one minute in a flow of $\left.\mathrm{O}_{2}\right)$, whereas the other was exposed to air for 72 hours. The TEM grids were then transferred to a Tecnai T20 G2 transmission electron microscope for bright-field imaging. Using the software "ImageJ", the TEM images were subsequently analyzed to obtain size distributions of the deposited nanoparticles. The results were filtered, in order to exclude particles that had landed on top of each other during the deposition. 


\section{Synchrotron radiation spectroscopy measurements}

All synchrotron measurements were carried out at Stanford Synchrotron Radiation Lightsource (SSRL) at SLAC National Laboratory in California, USA. High energy resolution fluorescence detected X-ray absorption spectroscopy (HERFD-XAS) was performed at beam line 6-2, a hard X-ray wiggler beam line equipped with a Si(111) monochromator in the $\phi=0^{\circ}$ setting. The spectrometer was of the Johann type with 7 bent $\mathrm{Si}(553)$ single crystals and equipped with a Vortex fluorescence detector ${ }^{47}$. The intensity of the incoming and transmitted beams was detected using ion chambers. HERFD-XAS was measured at the Ir $\mathrm{L}_{3}$-edge $(11215 \mathrm{eV})$ on the $2 \AA$ IrO $\mathrm{x} / \mathrm{RuO}_{2} / \mathrm{GC}$ sample, focusing on the $\mathrm{X}$-ray absorption near edge spectrum (XANES) only.

Conventional XAS measurements were made at beam line 14-3, a tender X-ray (2-5 keV) bending magnet source equipped with a $\mathrm{Si}(111)$ monochromator in the $\phi=0^{\circ}$ setting. A 4-element Vortex detector was used for fluorescence detection and an ion chamber was used for initial beam intensity detection. Due to the low photon energy, the entire beam path was in a He atmosphere at 1 bar to reduce absorption. At this beam line $\mathrm{Ru} \mathrm{L}_{3}$-edge (2838 eV) XANES were measured on the Ru NP/GC and $\mathrm{RuO}_{2} \mathrm{NP} / \mathrm{GC}$ samples.

All experiments were done in an operando cell, and two different setups were used at the Ir and $\mathrm{Ru}$ $\mathrm{L}_{3}$-edges due to the difference in photon energy and thereby different absorbance from the electrolyte. For the Ir L3-edge experiments we used a hanging meniscus setup developed at the Nilsson group at SLAC National Laboratory, which is described elsewhere ${ }^{48}$. The cell had a motorized 
syringe attached, so that the size of the meniscus could be controlled accurately, forming a cylindrically shaped meniscus $5 \mathrm{~mm}$ in diameter. The electrolyte used was $0.05 \mathrm{M} \mathrm{H}_{2} \mathrm{SO}_{4}$ with a Pt wire counter electrode and a $\mathrm{Ag} / \mathrm{AgCl}$ reference electrode (Innovative Instruments, Inc. LF-1.6, 3.4M $\mathrm{AgCl}$ ). To control the potentials a BioLogic potentiostat (BioLogic Scientific Instruments) was used, which was controlled by a separate PC.

For the Ru L3-edge experiments a back-illumination type cell was used, in which the detected X-rays only penetrate the electrode and not the electrolyte. We fabricated our own electrodes by pyrolyzing $8 \mu \mathrm{m}$ thick Kapton foil (DuPont) at $1000^{\circ} \mathrm{C}$ for 1 hour in a flow of $\mathrm{N}_{2}$. These windows were mounted in stainless steel frames to make handling easier, and a $7 \mathrm{~mm}$ diameter hole in the frame defined the active electrode area. Each frame was mounted on a $50 \mathrm{ml}$ high density polyethylene (HD-PE, Nalgene) bottle by epoxy glue, making sure to cover the steel frames completely with epoxy, thus decreasing the active electrode area slightly. Figure S1 in the supporting information (SI) shows pictures of the setup. To avoid the fluorescence from $\mathrm{S}$ in the electrolyte, we used $0.1 \mathrm{M} \mathrm{HNO}_{3}$ electrolyte for these experiments. The electrolyte, a Pt wire counter electrode, and a $\mathrm{Ag} / \mathrm{AgCl}$ reference electrode (identical to the Ir experiments) were all housed in the HD-PE bottle.

The mass-selected nanoparticles measured at the synchrotron were the same samples that were characterized by XPS in the preparation laboratory, i.e. the as-prepared Ru nanoparticles after exposure to air ( $5 \mathrm{~nm} \mathrm{Ru} \mathrm{NP/GC)}$ and the thermally oxidized $\mathrm{RuO}_{2}$ nanoparticles ( $5 \mathrm{~nm} \mathrm{RuO} 2 \mathrm{NP} / G C$ ). We have reported on the preparation and characterization of the $\operatorname{IrO} \mathrm{O}_{x}$ thin film $\left(2 \AA \operatorname{IrO} \mathrm{O}_{x} / \mathrm{RuO}_{2} / \mathrm{Au}\right)$ elsewhere ${ }^{37}$. 


\section{Simulating XAS spectra}

XAS spectra were simulated using version 9.6 of the FEFF software package ${ }^{49}$. All the simulations were run on the Abisko cluster, which is a part of the Swedish National Infrastructure for Computing (SNIC). We simulated the Ir $\mathrm{L}_{3}$ edge to compare to the measured spectra on the $2 \AA$ IrO $\mathrm{x} / \mathrm{RuO}_{2} / \mathrm{Au}$ sample. These measurements were done using the HERFD XAS technique that reduces the life-time broadening, and to compensate for this in our simulations we reduced the natural broadening by 1.5 eV.

The simulated surface was based on the rutile $\mathrm{RuO}_{2}(110)$ surface, but with the top-most Ru atoms in the surface replaced by Ir. The $2 \AA \operatorname{IrO} \times / \mathrm{RuO}_{2} / \mathrm{Au}$ sample was polycrystalline, but since the (110) surface is the most stable rutile surface, we chose to use this as the model surface. This surface has two different sites; one with $2 \mathrm{O}$ atoms below the surface, $2 \mathrm{O}$ in the surface, and 2 bridging $\mathrm{O}$ above the surface. The other site has 10 below the surface, 40 in the surface plane, and 10 above the surface, see Figure S2. At the potentials used in this experiment the bridge sites are assumed to be occupied by $\mathrm{O}^{34,35}$, whereas the different intermediates are found on the coordinatively unsaturated site (cus) on the second Ir site. To get the overall XAS spectra, both sites are simulated and their results averaged. To compare the white line positions of the simulations to those of the measurements, we fitted the simulated spectra using the same procedure as for the measurements. 


\section{Results}

The combined $\mathrm{IrO}_{\mathrm{x}} / \mathrm{RuO}_{2} / \mathrm{Au}$ system was structurally and electrochemically characterized previously, with results published in reference ${ }^{37}$.

To get more insight into the reaction mechanism of OER on $\mathrm{IrO}_{x}$ and $\mathrm{RuO}_{x}$ we fabricated metallic $\mathrm{Ru}$ and thermally oxidized $\mathrm{RuO}_{2}$ nanoparticles. These nanoparticles have been characterized previously in ${ }^{10}$, including GA-XRD showing crystallinity of both the as-deposited metallic and thermally oxidized particles. The $5 \mathrm{~nm}$ particles in this study are well dispersed and are quite round as seen in the TEM images in Figure S3a and S3b. The as-deposited metallic particles have a narrow size distribution of $4.9 \pm 0.3 \mathrm{~nm}$, whereas the oxidized particles have a size of $5.2 \pm 0.5 \mathrm{~nm}$ but with a tail towards large particle sizes, which could indicate coalescence of a small fraction of particles during the oxidation procedure. The size histograms and fitted size distributions are shown in Figure S3c. The change in particle volume does not correspond to a complete oxidation assuming Ru conservation. However, the as-prepared Ru nanoparticles were transported in air to the TEM, and from the XPS analysis we know that these nanoparticles are partially oxidized (see below). The thermally oxidized $\mathrm{RuO}_{2}$ nanoparticles show a well-ordered (from TEM) rutile structure (from GA-XRD) based on a previous study ${ }^{10}$, and this suggests that these nanoparticles are fully oxidized. Assuming a core-shell structure of the as-prepared Ru nanoparticles, based on the size change they consist of a $2.6 \mathrm{~nm}$ metallic core and a $1.15 \mathrm{~nm}$ thick oxide shell.

The nanoparticles were further characterized by XPS, and spectra were acquired before being exposed to air, after 72 hours of exposure to air, and the thermally oxidized samples after the oxidation procedure. Only C, O, N and Ru can be found in the survey spectra taken of both the 
metallic $\mathrm{Ru}$ after air exposure and oxidized $\mathrm{RuO}_{2}$ after annealing in the tube furnace (see Figure $\mathrm{S} 4$ ). Compared to the ruthenium peak energies after deposition ( $R u 3 d_{5 / 2}$ at $280.4 \mathrm{eV}$ and $\mathrm{Ru} 3 \mathrm{p}_{3 / 2}$ at 461.8 $\mathrm{eV}$ ) the peak energies in case of both samples appear to be shifted to higher binding energies (details about peak energies and peak fitting can be found in the supporting information). Figure 2 shows the overlapping C $1 s$ - Ru 3d peaks and the $\mathrm{Ru} 3 \mathrm{p}_{3 / 2}$ peak for the $\mathrm{Ru}$ and $\mathrm{RuO}_{2}$ samples. As expected the $\mathrm{RuO}_{2}$ sample has a larger binding energy shift, and thus appears to be more oxidized. The SI contains further details of the XPS characterization, including analysis of the Ru $3 p$ lines.

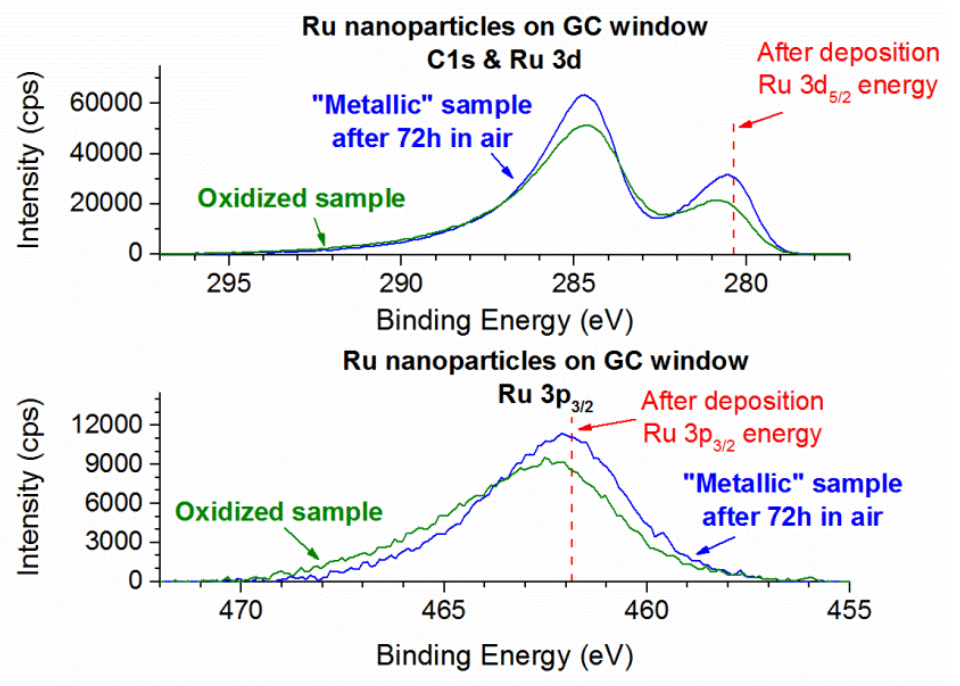

Figure 2. Detailed Ru 3d and $3 p_{3 / 2}$ XPS spectra of the Ru nanoparticles samples after subtraction of a Shirley-background.

XAS experiments were performed to gain further insight into the chemical state of Ir and Ru during OER. Figure 3 shows XAS spectra of the $2 \AA$ IrO $\mathrm{r}_{\mathrm{x}}$ on $40 \mathrm{~nm} \mathrm{RuO}$ thin film on a Au substrate $(2 \AA$ $\mathrm{IrO}_{\mathrm{x}} / \mathrm{RuO}_{2} / \mathrm{Au}$, Figure 3a), $5 \mathrm{~nm}$ mass-selected metallic Ru nanoparticles (5 nm Ru NP/GC, Figure 3b), 
and $5 \mathrm{~nm}$ mass-selected oxidized $\mathrm{RuO}_{2}$ nanoparticles ( $5 \mathrm{~nm} \mathrm{RuO} 2 \mathrm{NP} / \mathrm{GC}$, Figure 3c). These spectra are all acquired for the dry as-prepared samples, and they are compared to reference spectra of their respective metals and rutile oxides. The Ir metal and $\mathrm{IrO}_{2}$ references are both sputtered thin films, whereas the metallic Ru reference is a foil from the SSRL reference collection and the $\mathrm{RuO}_{2}$ reference is a powder (Sigma-Aldrich, 238058-1G, 99.9\% purity). The Ir XAS experiment was done using the HERFD XAS technique, and the Ir $L_{\alpha 1}$ emission line was measured prior to the experiment (see Figure S9), and the maximum intensity at $9175 \mathrm{eV}$ was chosen for all XAS spectra. This technique gives an effective life time broadening of $2.1 \mathrm{eV}^{50-52}$, which is similar to the intrinsic $\mathrm{L}_{3}$-edge life time broadening of $\mathrm{Ru}$ of $2.0 \mathrm{eV}^{51}$. The $\mathrm{IrO}_{\mathrm{x}}$ sample spectrum is very similar to that of the $\mathrm{IrO}_{2}$ reference (Figure 3a). The major difference is that the sharp peak just above the absorption edge (the white line) is more intense for the sample, which could be caused by polarization effects in the highly anisotropic $\mathrm{IrO}_{x}$ surface layer. The $\mathrm{RuO}_{2}$ mass-selected nanoparticles (Figure 3c) are similar to the $\mathrm{RuO}_{2}$ reference spectrum as expected. Again, the major difference is in the white line intensity, with the sample being more intense than the reference. The $\mathrm{RuO}_{2}$ reference spectrum reveals a splitting of the white line caused by a crystal field splitting of the $\mathrm{Ru} 4 \mathrm{~d}$ states ${ }^{53}$. But the $\mathrm{RuO}_{2}$ nanoparticles show this splitting to a much smaller degree, possibly due to a lower degree of crystallinity caused by the small size of the particles. At this point it is also worth noting that the $\mathrm{IrO}_{\mathrm{x}}$ does not display any crystal field splitting, consistent with conventional XAS measurements on Ir-compounds ${ }^{43,54,55}$. Finally, the metallic Ru nanoparticles (Figure 3b) are most similar to the metallic Ru reference as expected. However, the white line is much more intense than the reference, which we expect to be caused by the formation of a surface oxide, as observed by the XPS measurements discussed earlier. 

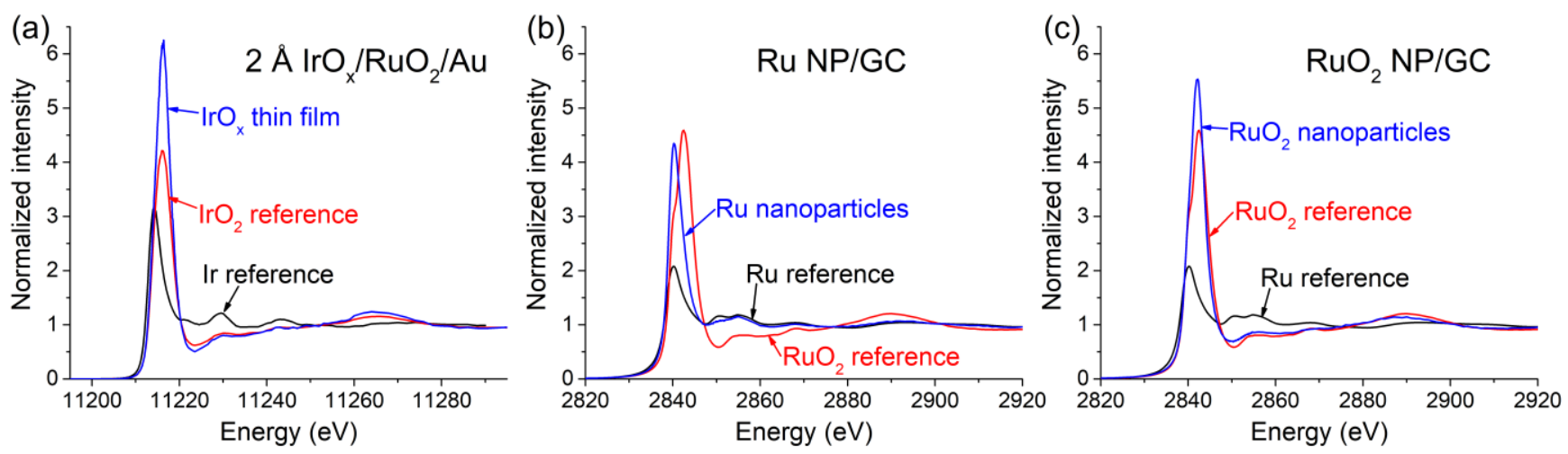

Figure 3. XAS spectra of (a) the $2 \AA I^{\prime} O_{x}$ on $40 \mathrm{~nm} \mathrm{RuO} 2$ thin film on a Au substrate $\left(2 \AA \mathrm{IrO}_{\mathrm{x}} / \mathrm{RuO}_{2} / \mathrm{Au}\right)$,

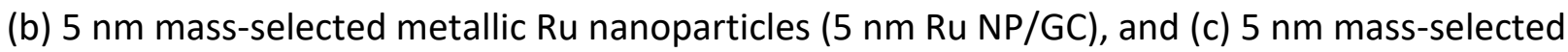
oxidized $\mathrm{RuO}_{2}$ nanoparticles ( $5 \mathrm{~nm} \mathrm{RuO}_{2} \mathrm{NP} / \mathrm{GC}$ ). They are compared to reference spectra of their respective metal and rutile oxide.

The operando XAS measurements of the $\mathrm{IrO}_{\mathrm{x}}$ sample were first done at open circuit potential, followed by XAS measurements at various fixed potentials, keeping the potential constant for the duration of each XAS measurement step. All the experimental potentials are given relative to RHE. The potential was first set to $0.5 \mathrm{~V}$ and then stepped up to $1.6 \mathrm{~V}$ in steps of $0.1 \mathrm{~V}$. The sample potential was increased directly, and there was no open circuit condition in between each step. Due to the bubble formation from the OER the meniscus was broken at $1.6 \mathrm{~V}$, and after restoring it the potential was set to $1.5 \mathrm{~V}$, and then stepped down to $0.6 \mathrm{~V}$ in steps of $0.1 \mathrm{~V}$. The potential was then set to $1.0 \mathrm{~V}$ and stepped up to $1.7 \mathrm{~V}$ in steps of $0.1 \mathrm{~V}$ (except between $1.6 \mathrm{~V}$ and $1.7 \mathrm{~V}$ where the step size was $0.05 \mathrm{~V}$ ), and this time the electrolyte meniscus stayed intact despite vigorous bubble formation. Figure $4 a$ shows the white line of the $2 \AA$ IrO $\mathrm{x}_{\mathrm{x}} / \mathrm{RuO}_{2} / \mathrm{Au}$ at different potentials, and it is 
seen that it shifts with the potential. Compared to the open circuit potential (OCV) the white line has shifted down, remained the same, and shifted up at $0.5 \mathrm{~V}, 0.9 \mathrm{~V}$, and $1.5 \mathrm{~V}$, respectively. Assuming these changes are caused by core-level shifts due to oxidation state changes, the shifts are equivalent to a reduction, no change, and an increased oxidation, respectively.

The operando XAS of the metallic Ru nanoparticles was performed in a similar way, first at OCV before any potential cycling, followed by OCV after 21 cycles from $0.8 \mathrm{~V}$ to $1.2 \mathrm{~V}$. The XAS measurements were then done at fixed potentials from $0.8 \mathrm{~V}$ to $1.4 \mathrm{~V}$ in steps of $0.1 \mathrm{~V}$ (except between $1.3 \mathrm{~V}$ and 1.4 $\mathrm{V}$, where the step size was $0.05 \mathrm{~V}$ ), and the potential was not turned to OCV in between potential steps. The white line at $\mathrm{OCV}, 0.8 \mathrm{~V}$, and $1.3 \mathrm{~V}$ is shown in Figure $4 \mathrm{~b}$. At $1.3 \mathrm{~V}$ a significant shoulder is seen towards high energy, indicating the growth of an oxide phase. This experiment was stopped after $1.4 \mathrm{~V}$ as the Ru had almost completely disappeared, see Figure S10a. In this case the loss of Ru is suspected to be mostly dissolution, as metallic Ru nanoparticles have proven quite unstable in acid ${ }^{10}$. Despite the dissolution the measurements are still informative of the OER reaction, as the current is dominated by $\mathrm{OER}^{10}$. Some $\mathrm{Cl}$ contamination was observed, as the $\mathrm{Cl} \mathrm{K}$-edge is only $\sim 16 \mathrm{eV}$ below the $\mathrm{Ru} \mathrm{L}_{3}$-edge. It is suspected to be in the form of organic $\mathrm{Cl}$ complexes dissolved from the epoxy glue used to mount the sample on the bottle. The amount of $\mathrm{Ru}$ and $\mathrm{Cl}$ was normalized to the amount of $\mathrm{Ru}$ at $0.8 \mathrm{~V}$. Cl evolution has a lower overpotential than $\mathrm{OER}^{56}$, and so the $\mathrm{Cl}$ we observe is not free $\mathrm{Cl}$ ions, as they would get evolved as chlorine gas and disappear immediately. The current during the experiment was not influenced by the $\mathrm{Cl}$ concentration, so the $\mathrm{Cl}$ did not interfere with the OER. 
Finally, the oxidized $\mathrm{RuO}_{2}$ nanoparticles were measured at OCV both before and after 5 cycles of the potential in the range $0.8 \mathrm{~V}$ to $1.2 \mathrm{~V}$. The white line at $\mathrm{OCV}, 0.8 \mathrm{~V}, 1.3 \mathrm{~V}$, and $1.7 \mathrm{~V}$ is shown in Figure 4c. The changes in the white line position are very small, which is due to a rather low surface to bulk ratio in the $5 \mathrm{~nm}$ particles. For this sample XAS was measured at fixed potential from $0.8 \mathrm{~V}$ to $1.3 \mathrm{~V}$, back to $0.8 \mathrm{~V}$, and up to $1.7 \mathrm{~V}$. Below $1.2 \mathrm{~V}$ the potential step size was $0.2 \mathrm{~V}$, and above it was $0.1 \mathrm{~V}$, and there were no OCV periods in between the potential steps. Figure S10b shows the Ru amount, which was much more stable than the other two Ru samples, but due to the longer running experiment the $\mathrm{Cl}$ contamination became quite high.
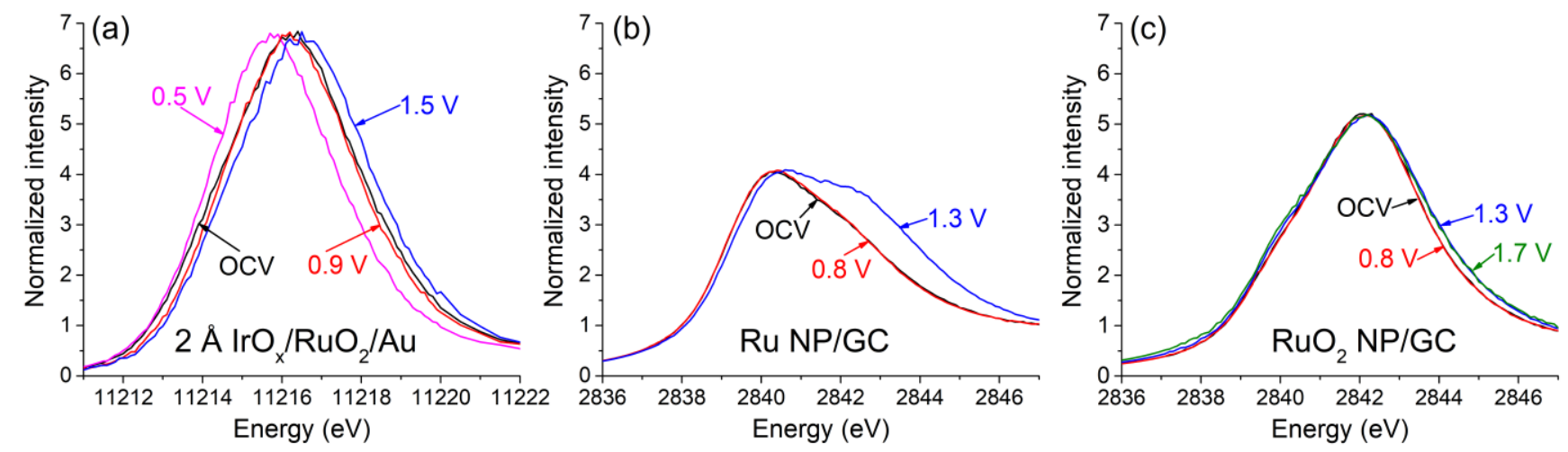

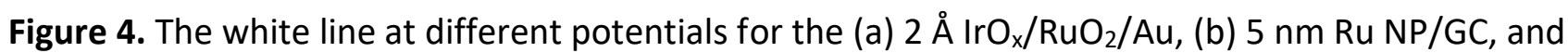
(c) $5 \mathrm{~nm} \mathrm{RuO} 2 \mathrm{NP} / \mathrm{GC}$. For the ultra-thin films of IrO $_{x}$ the white line moves significantly as a function potential, whereas for the nanoparticles the shift is smaller due to a smaller surface to bulk ratio. The metallic Ru nanoparticles get a shoulder towards high energy at $1.3 \mathrm{~V}$ due to the formation of an oxide phase. 
Figure 5 shows the white lines of the three samples at each potential, stacked on top of each other so that its position can be tracked from bottom to the top. The white lines of the ultra-thin film of $\mathrm{IrO}_{\mathrm{x}}$ follow the potential clearly as discussed above, and as indicated by the red dots. For the metallic Ru nanoparticles, the white line shape changes significantly at the OER and dissolution onset, until the oxide phase becomes dominant at $1.4 \mathrm{~V}$. The positions of the metallic and oxide peaks seen in the white lines are indicated by dashed red lines. The white line position of the oxidized $\mathrm{RuO}_{2}$ nanoparticles changes very little, but the trend is seen from the fitted (see below) peak position indicated by the red dots. Interestingly the white line shifts to slightly lower energy at the highest potentials.
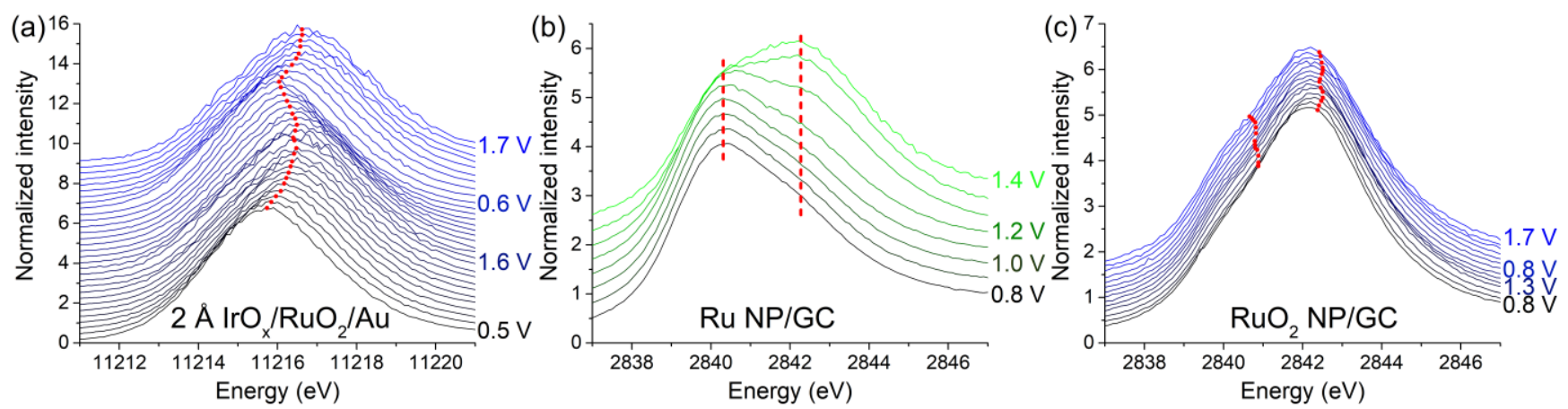

Figure 5. The white lines at each potential for (a) $2 \AA \mathrm{IrO}_{x} / \mathrm{RuO}_{2} / \mathrm{Au}$, (b) $5 \mathrm{~nm} \mathrm{Ru} \mathrm{NP/GC}$, and (c) $5 \mathrm{~nm}$ $\mathrm{RuO}_{2} \mathrm{NP} / \mathrm{GC}$. The white lines have been offset in the $y$-direction for clarity, and the beginning of each experiment is on the bottom and the end at the top. For (a) and (c) the red dots indicate the movement of the white line as a function of potential based on peak fitting. In (c) the white line is fitted by two peaks, therefore two sets of red dots are shown. For (b) the two dashed red lines show the positions of the metallic and oxide peaks in the white line. 
To interpret the changes in white line position, all the spectra have been quantified by curve fitting. The Ir spectra were fitted with an arctan function as the absorption step and a single Lorentzian for the white line itself. The arctan function was centered at the inflection point for each spectrum, and the Lorentzian peak was fitted by position, width, and height. For the Ru spectra, an arctan function was also used for the absorption step, and two Lorentzian peaks were used to fit the white line due to the crystal field splitting in $\mathrm{RuO}_{2}$ nanoparticles and coexistence of a metallic and oxide phase in the $\mathrm{Ru}$ nanoparticles. The arctan function was again centered at the inflection point of each spectrum, but to get stable fits the two Lorentzian peaks had their widths fixed at $2.8 \mathrm{eV}$ (FWHM), which agrees with the lifetime broadening ${ }^{51}$ and gave reasonable fits. The two peaks had their positions and heights fitted freely.

Figure 6 shows the white line Lorentzian peak positions as a function of electrochemical treatment along with the applied potential. For the Ir white lines the position of the single Lorentzian is shown, and for the Ru lines the peak position for the high-energy Lorentzian peak is shown. The error bars represent a confidence interval equivalent to $1 \sigma$ obtained from the fitting algorithm. For the Ru spectra additional error due to the $\mathrm{Cl}$ contamination was added by simulating the effect of adding a $\mathrm{Cl}$ spectrum to a pure Ru spectrum. The peak positions follow what was observed in the raw spectra, but for the $\mathrm{IrO}_{\mathrm{x}}$ sample it seems that the white line position does not change any further above 1.5 or 1.6 V. Similarly, for the metallic Ru nanoparticles the peak position saturates at $1.3 \mathrm{~V}$. For the $\mathrm{RuO}_{2}$ nanoparticles the peak position not only saturates at $1.3 \mathrm{~V}$, it even goes to lower energy. The 
inflection point found by center-of-mass analysis of the first derivative is shown in Figure S11 in the SI, and shows the same trends as discussed, just with a smaller movement in energy.

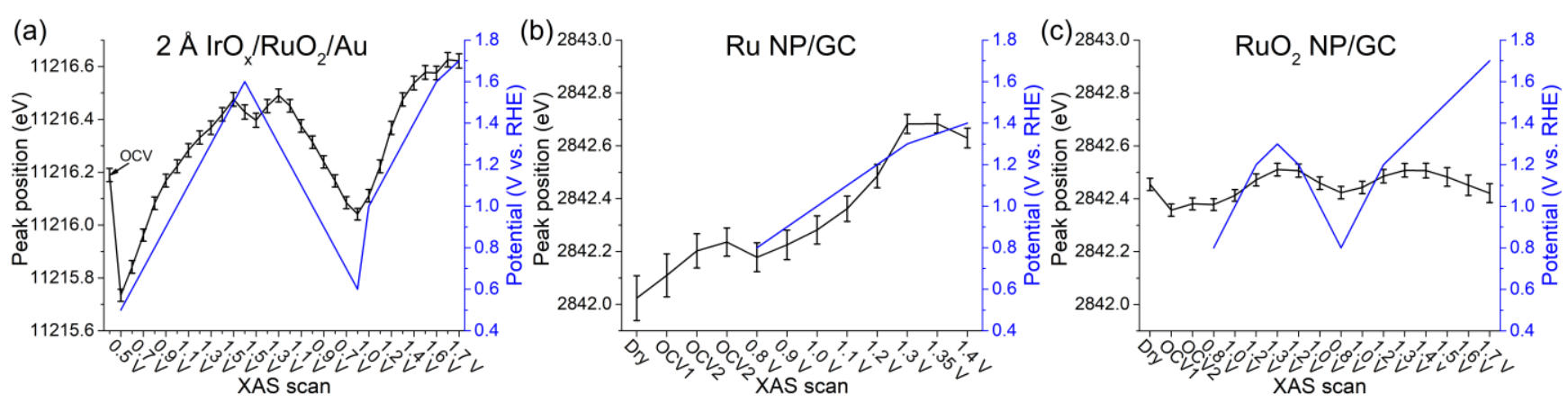

Figure 6. The white line position is shown from fitting the XAS spectra for (a) $2 \AA$ IrO $/ \mathrm{RuO}_{2} / \mathrm{Au}$, (b) 5 $\mathrm{nm} \mathrm{Ru} \mathrm{NP/GC}$, and (c) $5 \mathrm{~nm} \mathrm{RuO} 2 \mathrm{NP} / \mathrm{GC}$. For the Ir spectra the single Lorentzian peak position is shown, but for the Ru spectra only the high-energy Lorentzian peak position is shown, as it is the most dominant component.

As the XAS measurements here probe transitions from the $\operatorname{Ir}(\mathrm{Ru}) 2 \mathrm{p}$ states into empty $5 \mathrm{~d}$ and $6 \mathrm{~s}$ (4d and 5 s) states, the peak shifts can be caused either by changes in the initial or final state. The initial state energy may change when the absorbing atom changes oxidation state, leading to a core-level shift, whereas changes in the final state energy is tied to changes in the d-band. The XAS features above the white line are linked to the structure due to multiple scattering resonances, and so by comparing this region for different potentials we can see whether the whole spectrum has been shifted by a core-level shift, or if only the d-band has changed. 
Figure 7 shows the XAS features above the white line for the three samples. Multiple spectra at low potential and multiple spectra at high potentials have been averaged to provide a better signal-tonoise ratio. Furthermore, the high potential spectrum has been shifted down to align the white lines. The metallic Ru nanoparticles show signs of a changed structure, as the energy of the main feature at around $2890 \mathrm{eV}$ has changed and the peak at $\sim 2868 \mathrm{eV}$ disappears at high potential. This is not surprising, as the metallic Ru undergoes oxidation and forms an oxide phase. For the other two samples, there are no significant changes between the spectra at low and high potential, thus the white line shifts correspond to core-level shift entirely. This means that the shifts we observe are caused by oxidation state changes without any significant structural changes. The change in surface Ir oxidation state by the OER reaction is consistent with previously reported measurements ${ }^{42}$.
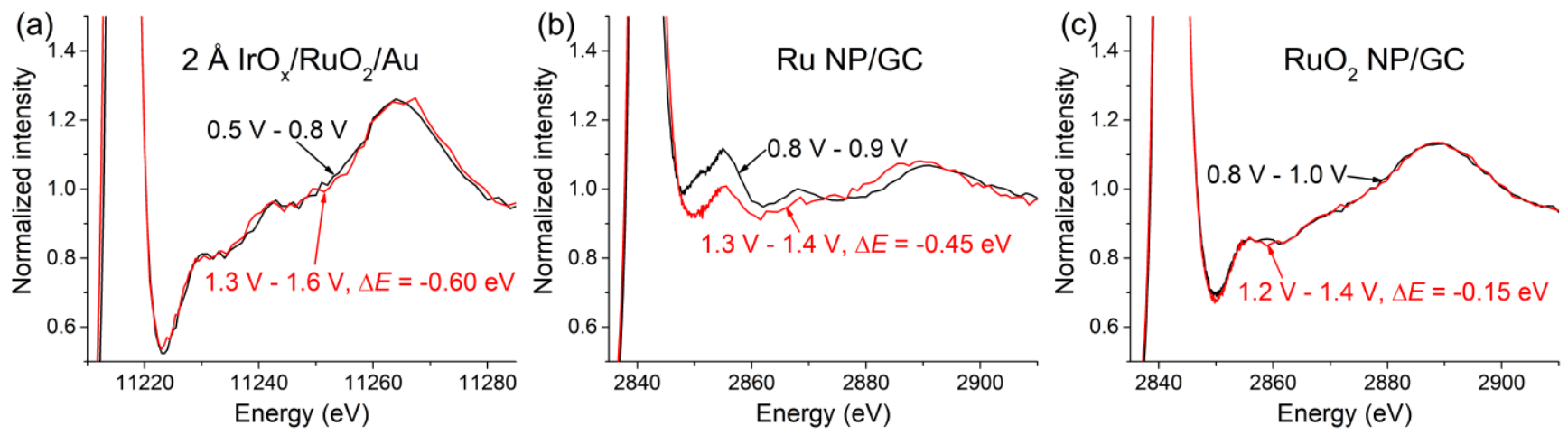

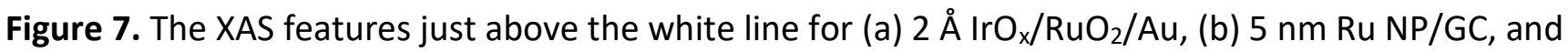
(c) $5 \mathrm{~nm} \mathrm{RuO} 2 \mathrm{NP} / \mathrm{GC}$. Any change in this region indicates structural changes, which is only seen in (b), as the metallic Ru nanoparticles oxidize under the measurement conditions. The lack of differences in the other spectra indicates no structural changes. The spectrum taken at high energy has been shifted 
to lower energy as indicated in the figure, and the amount is consistent with the core level shifts seen in Figure 6.

We investigated the link between the core level shift and the reaction intermediates further by simulating the XAS spectra obtained on the $2 \AA \mathrm{IrO} \times / \mathrm{RuO}_{2} / \mathrm{Au}$ system using FEFF. We used Ir-O bond lengths consistent with Ru-O bond lengths reported in references ${ }^{35,57,58}$, and the position of the white line is shown in Figure 8. Here it is seen that the majority of the core level shift is caused by the ${ }^{*} \mathrm{O}$ intermediate. Furthermore, the white line position is almost the same when the cus site is empty or covered by an ${ }^{*} \mathrm{OO}$ or ${ }^{*} \mathrm{OOH}$ intermediate. In order to be able to compare to other Ir-O bond lengths, we simulated a variety of bond lengths, and their white line positions are shown in Figure S12 in the SI. The error bars shown in Figure 8 are determined from fitting the simulated spectra with an arctan and Lorentzian peak like the measured spectra. The FEFF simulation tool does not provide estimates of the error in the simulation, and the absolute white line position is generally not very accurate in these types of simulations. However, as the atomic system is the same in all simulations, except for the adsorbed reaction intermediate, we believe that the relative error between the white line positions is on the order of the fitting errors. 


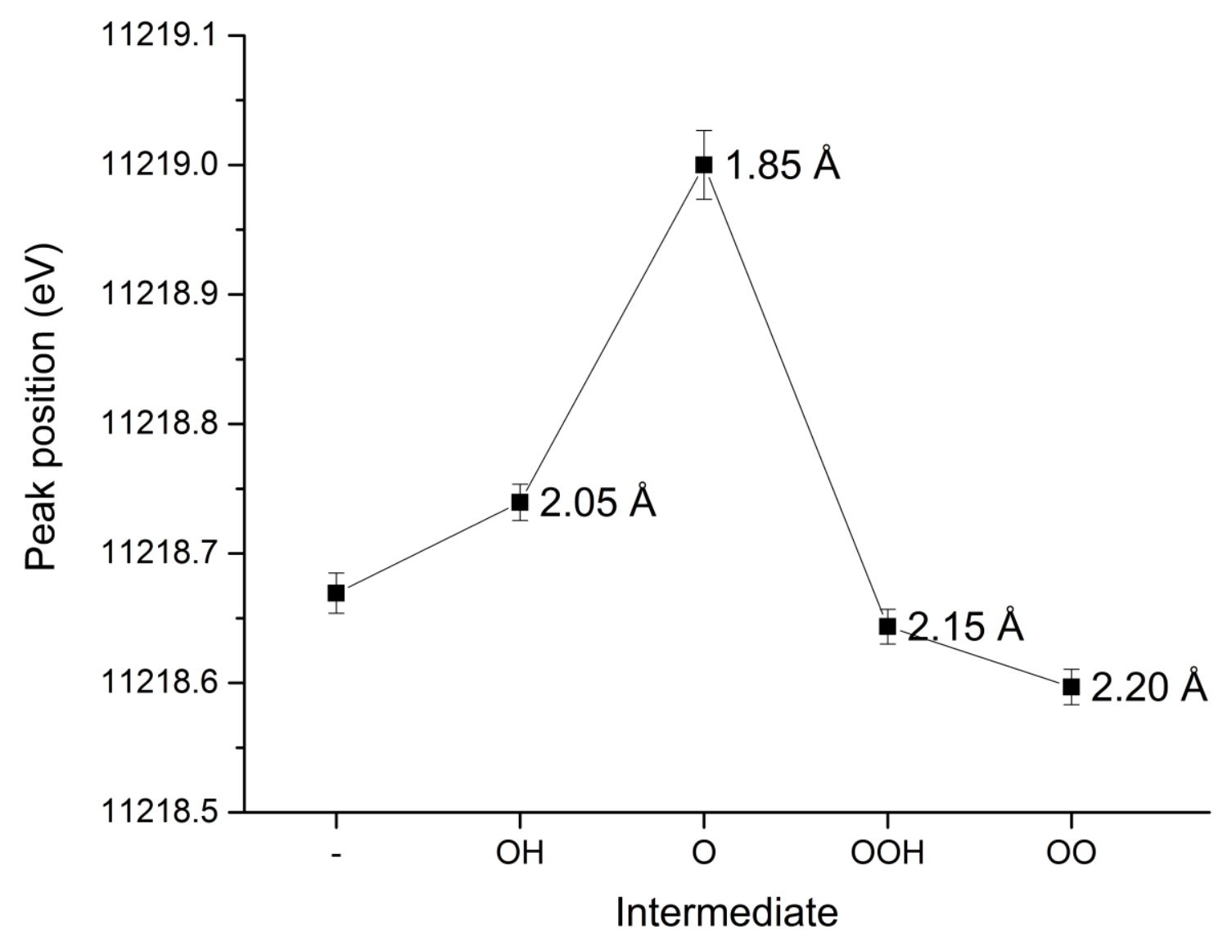

Figure 8. The figure shows the position of the white line of simulated XAS spectra for surface configurations with different reaction intermediates. The distances indicate the Ir-O bond length of the given intermediate. The error bars are from fitting the simulated spectra using the same procedure as the measured XAS spectra.

The FEFF simulations also show that the measurements agree with a reaction mechanism involving a significant coverage of an *OO based intermediate during OER, as this gives rise to a white line 
position almost identical to that of an empty cus site. So spectroscopically it would not be possible to determine whether this intermediate is present, but the results we have are consistent with its presence. The measured shift in the Ir white line is slightly higher than predicted by FEFF, but as the detailed spectroscopic shape around the absorption edge is difficult to calculate the inconsistency is within expected errors.

\section{Discussion}

In here we demonstrated that the shift in white line position is primarily cause by a core level binding energy shift, based on a comparison with multiple scattering resonances showing a similar shift as the white line. On this basis we can interpret the data in accordance with the proposed DFT based model of Rossmeisl et $\mathrm{al}^{29-31}$, which shows that the overpotential of $\operatorname{IrO}_{2}(110)$ is due to the conversion of *O to ${ }^{*} \mathrm{OOH} .{ }^{30}$ We observed that the oxidation state of $\mathrm{IrO}_{\mathrm{x}}$, manifested as the $\mathrm{Ir}$ white line position, is saturated at high overpotentials. According to the FEFF simulations shown in Figure 8 , adsorbed *0 causes a markedly more positive shift in the white line position than other adsorbates. Consequently, the white line position is a measure of the ${ }^{*} O$ coverage. In this case the oxidation state increases with increasing potential, as the surface gets further covered by * $O$. At OER potentials the white line position saturates, which indicates that the surface gets fully covered with adsorbed $\mathrm{O}$ that are not turning over to form $\mathrm{OO}$ and therefore it would be desirable to destabilize the adsorbed $\mathrm{O}$ in future catalyst designs. This core level shift is in agreement with previous operando $\mathrm{x}$-ray photoelectron spectroscopy studies of $\mathrm{IrO}_{2}$ nanoparticles ${ }^{42}$, which also showed from photon energy dependent spectral sensitivity that the change of oxidation state occurs in the topmost Ir layer. 
In contrast to $\mathrm{IrO}_{2}$, in the case of $\mathrm{RuO}_{2}$ we observe a decrease in oxidation state beyond $1.5 \mathrm{~V}$. At first glance, this phenomenon could seem counterintuitive. However, it is in fact consistent with the proposed DFT based model shown in Figure 1. In this case the energetically most stable intermediate just below the onset of OER is atomic * $\mathrm{O}$, and a full coverage of $* \mathrm{O}$ will bring the Ru in the highest average oxidation state. As the potential is increased somewhat above the potential where all the reaction steps are all downhill in energy, the coverage of * $O$ is now determined by the kinetics of the reaction rather than the thermodynamic stability of each intermediate. As seen in Figure 1 the most difficult step is to go from ${ }^{*} \mathrm{O}$ to ${ }^{*} \mathrm{OOH}$, but when the step is overcome the driving force to evolve $\mathrm{O}_{2}$ gas is very high. Similarly, when the first water molecule is adsorbed to form *OH the further oxidation to * $\mathrm{O}$ has a large driving force. Therefore, during OER the two dominant states of Ru are empty sites $\left({ }^{*}\right)$ and covered by atomic $* 0$. In the limit of similar reaction rates for ${ }^{*} \rightarrow^{*} \mathrm{O}$ and $* \mathrm{O} \rightarrow \mathrm{O}_{2}(\mathrm{~g})$ the coverage of $* \mathrm{O}$ is $50 \%$. And this lower coverage of $* \mathrm{O}$ leads to a lower average oxidation state of $\mathrm{Ru}$, explaining the measured reduction in $\mathrm{Ru}$ oxidation state.

It is interesting to note that we do not observe a decrease in oxidation state on $\mathrm{IrO}_{2}$, which, according to theoretical calculations, is also limited by ${ }^{*} \mathrm{OOH}$ formation ${ }^{30}$. However, our experimental observation is consistent with the notion that the overpotential required to drive the reaction is higher on $\mathrm{IrO}_{2}$ than $\mathrm{RuO}_{2}$. On this basis, we would expect that $\mathrm{IrO}_{2}$ would also exhibit a decrease in oxidation state at even higher overpotentials. 


\section{Conclusion}

We measured operando XAS spectra on $\mathrm{RuO}_{\mathrm{x}}$ based nanoparticles and a $\mathrm{IrO} \mathrm{X}_{\mathrm{x}} / \mathrm{RuO}_{2}$ thin film, as a function of electrochemical potential. We found that the observed changes in the spectra are primarily due to core level shifts caused by changes in the oxidation state. An exception was metallic Ru nanoparticles, which went through structural changes when forming an oxide phase at high electrochemical potentials. The changes in oxidation state are consistent with an earlier, DFT based reaction mechanism proposed by Rossmeisl, Nørskov and coworkers ${ }^{29-31}$.

Simulations of the XAS spectra showed that the average oxidation state changes were dominated by the coverage of an atomic $\mathrm{O}$ intermediate. The $\mathrm{IrO}_{\mathrm{x}}$ showed a saturation of the oxidation state at high electrochemical potentials, meaning that the surface is fully covered by $\mathrm{O}$, consistent with $\operatorname{IrO}_{\mathrm{x}}$ binding $\mathrm{O}$ too strongly.

The decrease in oxidation state that occurred for the $\mathrm{RuO}_{2}$ nanoparticles is rationalized by $\mathrm{RuO}_{2}$ binding the atomic $\mathrm{O}$ intermediate too strong compared to the optimum, but weaker than $\operatorname{IrO}_{\mathrm{x}}$ In this case the surface will be covered by atomic $\mathrm{O}$ at potentials just below the OER onset, giving the maximum average oxidation state, and during OER the coverage of atomic $\mathrm{O}$ will decrease as the active sites are turning over oxygen gas. These observations limit the Ru-O bond strength to be weaker than the Ir-O bond strength, but still stronger than the optimum metal-oxygen bond for OER. 


\section{Associated content}

Supporting information contains more detailed information on the experimental procedure, sample preparation, and sample characterization.

\section{Acknowledgement}

For funding of this work, we gratefully acknowledge the European Union's Seventh Framework Programme (FP7/2007-2013) under grant agreement no. 607417 (Catsense). We also gratefully acknowledge the Villum Foundation for V-SUSTAIN grant 9455 to the Villum Center for the Science of Sustainable Fuels and Chemicals. The Danish Ministry of Higher Education and Science is acknowledged for an EliteForsk travel grant making an extended stay at SLAC possible. Use of the Stanford Synchrotron Radiation Lightsource, SLAC National Accelerator Laboratory, is supported by the U.S. Department of Energy, Office of Science, Office of Basic Energy Sciences under Contract No. DE-AC02-76SF00515. Computational resources provided by the Swedish National Infrastructure for Computing (SNIC) at the HP2CN center are gratefully acknowledged. M.E.-E. acknowledges the Danish Council for Independent Research for her Individual Postdoctoral and Sapere Aude: Research Talent grants.

\section{References}

(1) Obama, B. The Irreversible Momentum of Clean Energy. Science 2017, aam6284.

(2) Lewis, N. S.; Nocera, D. G. Powering the Planet: Chemical Challenges in Solar Energy Utilization. Proc. Natl. Acad. Sci. 2006, 103 (43), 15729-15735. 
(3) Benck, J. D.; Hellstern, T. R.; Kibsgaard, J.; Chakthranont, P.; Jaramillo, T. F. Catalyzing the Hydrogen Evolution Reaction (HER) with Molybdenum Sulfide Nanomaterials. ACS Catal. 2014, 4 (11), 3957-3971.

(4) Kortlever, R.; Shen, J.; Schouten, K. J. P.; Calle-Vallejo, F.; Koper, M. T. M. Catalysts and Reaction Pathways for the Electrochemical Reduction of Carbon Dioxide. J. Phys. Chem. Lett. 2015, 6 (20), 40734082.

(5) Russell, A. E.; Rose, A. X-ray Absorption Spectroscopy of Low Temperature Fuel Cell Catalysts. Chem. Rev. 2004, 104 (10), 4613-4636.

(6) Carmo, M.; Fritz, D. L.; Mergel, J.; Stolten, D. A Comprehensive Review on PEM Water Electrolysis. Int. J. Hydrog. Energy 2013, 38 (12), 4901-4934.

(7) Holladay, J. D.; Hu, J.; King, D. L.; Wang, Y. An Overview of Hydrogen Production Technologies. Catal. Today 2009, 139 (4), 244-260.

(8) Seitz, L. C.; Dickens, C. F.; Nishio, K.; Hikita, Y.; Montoya, J.; Doyle, A.; Kirk, C.; Vojvodic, A.; Hwang, H. Y.; Norskov, J. K.; et al. A Highly Active and Stable IrOx/SrIrO3 Catalyst for the Oxygen Evolution Reaction. Science 2016, 353 (6303), 1011-1014.

(9) McCrory, C. C. L.; Jung, S.; Peters, J. C.; Jaramillo, T. F. Benchmarking Heterogeneous Electrocatalysts for the Oxygen Evolution Reaction. J. Am. Chem. Soc. 2013, 135 (45), 16977-16987.

(10) Paoli, E. A.; Masini, F.; Frydendal, R.; Deiana, D.; Schlaup, C.; Malizia, M.; Hansen, T. W.; Horch, S.; Stephens, I. E. L.; Chorkendorff, I. Oxygen Evolution on Well-Characterized Mass-Selected Ru and RuO2 Nanoparticles. Chem. Sci. 2014.

(11) Danilovic, N.; Subbaraman, R.; Chang, K.-C.; Chang, S. H.; Kang, Y. J.; Snyder, J.; Paulikas, A. P.; Strmcnik, D.; Kim, Y.-T.; Myers, D.; et al. Activity-Stability Trends for the Oxygen Evolution Reaction on Monometallic Oxides in Acidic Environments. J. Phys. Chem. Lett. 2014, 5 (14), 2474-2478.

(12) Burke, L. D.; Murphy, O. J.; O’Neill, J. F.; Venkatesan, S. The Oxygen Electrode. Part 8.-Oxygen Evolution at Ruthenium Dioxide Anodes. J. Chem. Soc. Faraday Trans. 1 Phys. Chem. Condens. Phases 1977, 73 (0), 1659-1671.

(13) Trasatti, S. Electrocatalysis: Understanding the Success of DSA ${ }^{\circledR}$. Electrochimica Acta 2000, 45 (15-16), 2377-2385.

(14) Mei, B.; Seger, B.; Pedersen, T.; Malizia, M.; Hansen, O.; Chorkendorff, I.; Vesborg, P. C. K. Protection of P+-N-Si Photoanodes by Sputter-Deposited Ir/IrOx Thin Films. J. Phys. Chem. Lett. 2014, 5 (11), 19481952.

(15) Vesborg, P. C. K.; Jaramillo, T. F. Addressing the Terawatt Challenge: Scalability in the Supply of Chemical Elements for Renewable Energy. RSC Adv. 2012, 2 (21), 7933-7947.

(16) Horkans, J.; Shafer, M. W. An Investigation of the Electrochemistry of a Series of Metal Dioxides with Rutile-Type Structure: MoO2, WO 2, ReO2, RuO2, OsO2, and IrO2. J. Electrochem. Soc. 1977, 124 (8), 1202-1207.

(17) Stoerzinger, K. A.; Qiao, L.; Biegalski, M. D.; Shao-Horn, Y. Orientation-Dependent Oxygen Evolution Activities of Rutile IrO2 and RuO2. J. Phys. Chem. Lett. 2014, 5 (10), 1636-1641.

(18) Stoerzinger, K. A.; Diaz-Morales, O.; Kolb, M.; Rao, R. R.; Frydendal, R.; Qiao, L.; Wang, X. R.; Halck, N. B.; Rossmeisl, J.; Hansen, H. A.; et al. Orientation-Dependent Oxygen Evolution on RuO2 Without Lattice Exchange. ACS Energy Lett. 2017, 2 (4), 876-881.

(19) Kuo, D.-Y.; Kawasaki, J. K.; Nelson, J. N.; Kloppenburg, J.; Hautier, G.; Shen, K. M.; Schlom, D. G.; Suntivich, J. Influence of Surface Adsorption on the Oxygen Evolution Reaction on IrO2(110). J. Am. Chem. Soc. 2017, 139 (9), 3473-3479.

(20) Trasatti, S. Electrocatalysis in the Anodic Evolution of Oxygen and Chlorine. Electrochimica Acta 1984, 29 (11), 1503-1512. 
(21) Kötz, R.; Stucki, S. Stabilization of RuO2 by IrO2 for Anodic Oxygen Evolution in Acid Media.

Electrochimica Acta 1986, 31 (10), 1311-1316.

(22) Reier, T.; Oezaslan, M.; Strasser, P. Electrocatalytic Oxygen Evolution Reaction (OER) on Ru, Ir, and Pt Catalysts: A Comparative Study of Nanoparticles and Bulk Materials. ACS Catal. 2012, 2 (8), 1765-1772.

(23) Ayers, K. E.; Dalton, L. T.; Anderson, E. B. (Invited) Efficient Generation of High Energy Density Fuel from Water. ECS Trans. 2012, 41 (33), 27-38.

(24) Cherevko, S.; Zeradjanin, A. R.; Topalov, A. A.; Kulyk, N.; Katsounaros, I.; Mayrhofer, K. J. J. Dissolution of Noble Metals During Oxygen Evolution in Acidic Media. ChemCatChem 2014, 6 (8), 2219-2223.

(25) Cherevko, S.; Geiger, S.; Kasian, O.; Kulyk, N.; Grote, J.-P.; Savan, A.; Shrestha, B. R.; Merzlikin, S.; Breitbach, B.; Ludwig, A.; et al. Oxygen and Hydrogen Evolution Reactions on Ru, RuO2, Ir, and IrO2 Thin Film Electrodes in Acidic and Alkaline Electrolytes: A Comparative Study on Activity and Stability. Catal. Today 2016, 262, 170-180.

(26) Paoli, E. A.; Masini, F.; Frydendal, R.; Deiana, D.; Malacrida, P.; Hansen, T. W.; Chorkendorff, I.; Stephens, I. E. L. Fine-Tuning the Activity of Oxygen Evolution Catalysts: The Effect of Oxidation Pre-Treatment on Size-Selected Ru Nanoparticles. Catal. Today 2016, 262, 57-64.

(27) Reier, T.; Nong, H. N.; Teschner, D.; Schlögl, R.; Strasser, P. Electrocatalytic Oxygen Evolution Reaction in Acidic Environments - Reaction Mechanisms and Catalysts. Adv. Energy Mater. 2017, 7 (1), 1601275. Wang, L.; Saveleva, V. A.; Zafeiratos, S.; Savinova, E. R.; Lettenmeier, P.; Gazdzicki, P.; Gago, A. S.; Friedrich, K. A. Highly Active Anode Electrocatalysts Derived from Electrochemical Leaching of Ru from Metallic Ir0.7Ru0.3 for Proton Exchange Membrane Electrolyzers. Nano Energy 2017, 34, 385-391. Rossmeisl, J.; Logadottir, A.; Nørskov, J. K. Electrolysis of Water on (Oxidized) Metal Surfaces. Chem. Phys. 2005, 319 (1-3), 178-184.

Rossmeisl, J.; Qu, Z.-W.; Zhu, H.; Kroes, G.-J.; Nørskov, J. K. Electrolysis of Water on Oxide Surfaces. J. Electroanal. Chem. 2007, 607 (1-2), 83-89.

Man, I. C.; Su, H.-Y.; Calle-Vallejo, F.; Hansen, H. A.; Martínez, J. I.; Inoglu, N. G.; Kitchin, J.; Jaramillo, T. F.; Nørskov, J. K.; Rossmeisl, J. Universality in Oxygen Evolution Electrocatalysis on Oxide Surfaces. ChemCatChem 2011, 3 (7), 1159-1165.

Friebel, D.; Viswanathan, V.; Miller, D. J.; Anniyev, T.; Ogasawara, H.; Larsen, A. H.; O’Grady, C. P.; Nørskov, J. K.; Nilsson, A. Balance of Nanostructure and Bimetallic Interactions in Pt Model Fuel Cell Catalysts: In Situ XAS and DFT Study. J. Am. Chem. Soc. 2012, 134 (23), 9664-9671.

Merte, L. R.; Behafarid, F.; Miller, D. J.; Friebel, D.; Cho, S.; Mbuga, F.; Sokaras, D.; Alonso-Mori, R.; Weng, T.-C.; Nordlund, D.; et al. Electrochemical Oxidation of Size-Selected Pt Nanoparticles Studied Using in Situ High-Energy-Resolution X-ray Absorption Spectroscopy. ACS Catal. 2012, 2 (11), 23712376.

(34) Ping, Y.; Nielsen, R. J.; Goddard, W. A. The Reaction Mechanism with Free Energy Barriers at Constant Potentials for the Oxygen Evolution Reaction at the IrO2 (110) Surface. J. Am. Chem. Soc. 2017, 139 (1), 149-155.

(35) Rao, R. R.; Kolb, M. J.; Halck, N. B.; Pedersen, A. F.; Mehta, A.; You, H.; Stoerzinger, K. A.; Feng, Z.; Hansen, H. A.; Zhou, H.; et al. Exploring the Pre-Oxygen Evolution Surface Chemistry on RuO2 (110). Submitted.

(36) Pratontep, S.; Carroll, S. J.; Xirouchaki, C.; Streun, M.; Palmer, R. E. Size-Selected Cluster Beam Source Based on Radio Frequency Magnetron Plasma Sputtering and Gas Condensation. Rev. Sci. Instrum. 2005, 76 (4), 045103.

(37) Escudero-Escribano, M.; Pedersen, A. F.; Paoli, E. A.; Frydendal, R.; Stephens, I. E. L.; Chorkendorff, I. Enhanced Stability of RuO2 in Acidic Oxygen Evolution Using IrOx. J. Phys. Chem. B (Submitted). 
(38) Jiang, P.; Bao, X.; Salmeron, M. Catalytic Reaction Processes Revealed by Scanning Probe Microscopy. Acc. Chem. Res. 2015, 48 (5), 1524-1531.

(39) Wu, C. H.; Eren, B.; Salmeron, M. B. Structure and Dynamics of Reactant Coadsorption on Single Crystal Model Catalysts by HP-STM and AP-XPS: A Mini Review. Top. Catal. 2016, 59 (5-7), 405-419.

(40) Wu, C. H.; Weatherup, R. S.; Salmeron, M. B. Probing Electrode/Electrolyte Interfaces In Situ by X-ray Spectroscopies: Old Methods, New Tricks. Phys. Chem. Chem. Phys. 2015, 17 (45), 30229-30239.

(41) Abbott, D. F.; Lebedev, D.; Waltar, K.; Povia, M.; Nachtegaal, M.; Fabbri, E.; Copéret, C.; Schmidt, T. J. Iridium Oxide for the Oxygen Evolution Reaction: Correlation between Particle Size, Morphology, and the Surface Hydroxo Layer from Operando XAS. Chem. Mater. 2016, 28 (18), 6591-6604.

(42) Sanchez Casalongue, H. G.; Ng, M. L.; Kaya, S.; Friebel, D.; Ogasawara, H.; Nilsson, A. In Situ Observation of Surface Species on Iridium Oxide Nanoparticles during the Oxygen Evolution Reaction. Angew. Chem. 2014, 126 (28), 7297-7300.

(43) Sardar, K.; Petrucco, E.; Hiley, C. I.; Sharman, J. D. B.; Wells, P. P.; Russell, A. E.; Kashtiban, R. J.; Sloan, J.; Walton, R. I. Water-Splitting Electrocatalysis in Acid Conditions Using Ruthenate-Iridate Pyrochlores. Angew. Chem. Int. Ed. 2014, 53 (41), 10960-10964.

(44) Issendorff, B. von; Palmer, R. E. A New High Transmission Infinite Range Mass Selector for Cluster and Nanoparticle Beams. Rev. Sci. Instrum. 1999, 70 (12), 4497-4501.

(45) Hernandez-Fernandez, P.; Masini, F.; McCarthy, D. N.; Strebel, C. E.; Friebel, D.; Deiana, D.; Malacrida, P.; Nierhoff, A.; Bodin, A.; Wise, A. M.; et al. Mass-Selected Nanoparticles of PtxY as Model Catalysts for Oxygen Electroreduction. Nat. Chem. 2014, 6 (8), 732-738.

(46) Masini, F.; Hernández-Fernández, P.; Deiana, D.; Strebel, C. E.; McCarthy, D. N.; Bodin, A.; Malacrida, P.; Stephens, I.; Chorkendorff, I. Exploring the Phase Space of Time of Flight Mass Selected PtxY Nanoparticles. Phys. Chem. Chem. Phys. 2014, 16 (48), 26506-26513.

(47) Sokaras, D.; Weng, T.-C.; Nordlund, D.; Alonso-Mori, R.; Velikov, P.; Wenger, D.; Garachtchenko, A.; George, M.; Borzenets, V.; Johnson, B.; et al. A Seven-Crystal Johann-Type Hard X-ray Spectrometer at the Stanford Synchrotron Radiation Lightsource. Rev. Sci. Instrum. 2013, 84 (5), 053102.

(48) Friebel, D.; Miller, D. J.; O’Grady, C. P.; Anniyev, T.; Bargar, J.; Bergmann, U.; Ogasawara, H.; Wikfeldt, K. T.; Pettersson, L. G. M.; Nilsson, A. In Situ X-ray Probing Reveals Fingerprints of Surface Platinum Oxide. Phys. Chem. Chem. Phys. 2010, 13 (1), 262-266.

(49) Rehr, J. J.; Kas, J. J.; Vila, F. D.; Prange, M. P.; Jorissen, K. Parameter-Free Calculations of X-ray Spectra with FEFF9. Phys. Chem. Chem. Phys. 2010, 12 (21), 5503-5513.

(50) de Groot, F. M. F.; Krisch, M. H.; Vogel, J. Spectral Sharpening of the Pt L Edges by High-Resolution X-ray Emission. Phys. Rev. B 2002, 66 (19), 195112.

(51) Krause, M. O.; Oliver, J. H. Natural Widths of Atomic K and L Levels, Ka X-ray Lines and Several KLL Auger Lines. J. Phys. Chem. Ref. Data 1979, 8 (2), 329-338.

(52) Papp, T.; Campbell, J. L.; Varga, D. X-ray Natural Widths, Level Widths and Coster-Kronig Transition Probabilities. In AIP Conference Proceedings; AIP Publishing, 1997; Vol. 389, pp 431-446.

(53) Hu, Z.; von Lips, H.; Golden, M. S.; Fink, J.; Kaindl, G.; de Groot, F. M. F.; Ebbinghaus, S.; Reller, A. Multiplet Effects in the Ru $\$\{L\} \_\{2,3\} \$$ X-ray-Absorption Spectra of Ru(IV) and Ru(V) Compounds. Phys. Rev. B 2000, 61 (8), 5262-5266.

(54) Clancy, J. P.; Chen, N.; Kim, C. Y.; Chen, W. F.; Plumb, K. W.; Jeon, B. C.; Noh, T. W.; Kim, Y.-J. Spin-Orbit Coupling in Iridium-Based $5 \$ \mathrm{~d} \$$ Compounds Probed by X-ray Absorption Spectroscopy. Phys. Rev. B 2012, 86 (19), 195131.

(55) Minguzzi, A.; Locatelli, C.; Cappelletti, G.; Scavini, M.; Vertova, A.; Ghigna, P.; Rondinini, S. IrO2-Based Disperse-Phase Electrocatalysts: A Complementary Study by Means of the Cavity-Microelectrode and ExSitu X-ray Absorption Spectroscopy. J. Phys. Chem. A 2012, 116 (25), 6497-6504. 
(56) Hansen, H. A.; Man, I. C.; Studt, F.; Abild-Pedersen, F.; Bligaard, T.; Rossmeisl, J. Electrochemical Chlorine Evolution at Rutile Oxide (110) Surfaces. Phys. Chem. Chem. Phys. 2009, 12 (1), 283-290.

(57) Kim, Y. D.; Seitsonen, A. P.; Wendt, S.; Wang, J.; Fan, C.; Jacobi, K.; Over, H.; Ertl, G. Characterization of Various Oxygen Species on an Oxide Surface: RuO2(110). J. Phys. Chem. B 2001, 105 (18), 3752-3758.

(58) McKeown, D. A.; Hagans, P. L.; Carette, L. P. L.; Russell, A. E.; Swider, K. E.; Rolison, D. R. Structure of Hydrous Ruthenium Oxides: Implications for Charge Storage. J. Phys. Chem. B 1999, 103 (23), 48254832. 
TOC Graphic

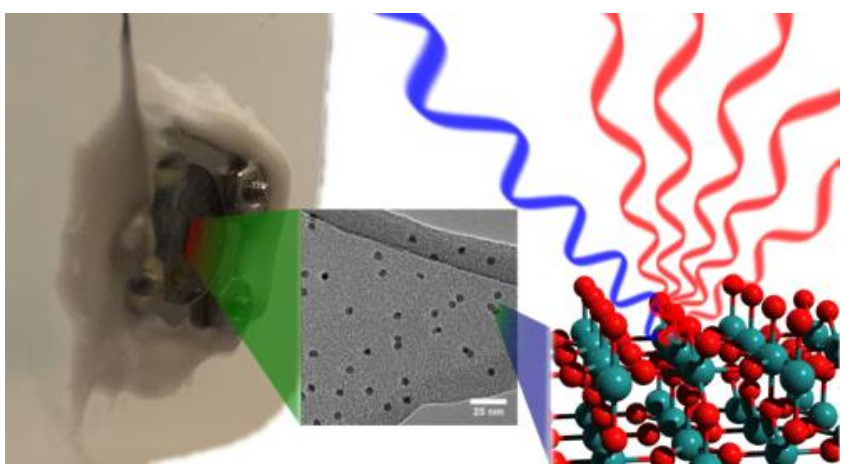

